\title{
Correlates of depressive disorders and quality of life among older adults in six low and middle- income countries: WHO country-wide study on global ageing and adult health
}

Duah Dwomoh ( $\nabla$ duahdwomoh@yahoo.com )

UNIVERSITY OF GHANA https://orcid.org/0000-0002-2726-9929

\section{Susan Ama Amuasi}

Centrall University College

Gabriel Incoom

Ghana Institute of Management and Public Administration

Alfred Edwin Yawson

University of Ghana

Emmanuel Asampong

University of Ghana

\section{Samuel Bosomprah}

University of Ghana

Research article

Keywords: Depressive disorders, quality of life, asthma

Posted Date: March 2nd, 2020

DOI: https://doi.org/10.21203/rs.3.rs-15573/v1

License: (c) (1) This work is licensed under a Creative Commons Attribution 4.0 International License.

Read Full License 


\section{Abstract}

Background The diagnosis and treatment of Depressive Disorders (DD) remain a challenge in low and middle-income countries (LMICs). Identifying the most important correlate of DD would serve as a guide in the design and implementation of targeted intervention in resource-constrained LMICs. This study determined whether there is/are common risk factor(s) of DD across the six LMICs and whether there is a risk factor that can be ranked consistently as the most important predictor of DD in all the six LMICs. We further estimated the impact of DD on the quality of life (QoL).

Methods We used data from the World Health Organization Study on Global Ageing and Adult Health. Weighted dominance analysis was performed to determine the most important risk factor of DD. We applied inverse probability weighting Poisson regression adjustment to estimate the impact of DD on QoL for each country and further estimated the overall effect of DD on QoL in the six countries by computing a weighted average of the country-specific estimate using the technique of meta-analysis.

Results Among the 58 risk factors investigated, Asthma was the most common and the most important predictor of DD across all six LMICs. DD contributed to a $12 \%$ increase in the poor QoL in China, (prevalence difference $(P D)=0.12 ; 95 \% \mathrm{Cl}: 0.07-0.18, p<0.001)$. In India ( $P D=0.08 ; 95 \%$ Cl: 0.04-0.13, $p<0.01)$ and Russian Federation ( $P D=0.08 ; 95 \% \mathrm{Cl}: 0.01-0.15, p<0.01)$. Although there was some increase in poor QoL in Mexico, Ghana, and South Africa due to DD, the increase was not statistically significant.

Conclusions Asthma is a major contributing factor to the high prevalence of DD among older adults and could have a direct or indirect effect on QoL. We recommend integrated intervention for Asthma patients that incorporates the diagnosis and treatment of DD. Access to quality mental healthcare should be a major government priority in LMICs.

\section{Background}

Poor quality of life (QoL) disrupt social functioning and fulfillment of basic needs and is associated with depressive disorders (DD) [1-3]. Approximately 350 million people are affected by DD each year and it was the fifth leading cause of global disease, accounting for approximately $12 \%$ of years of life lived with disabilities (YLDs) in 2016 [4]. Evidence suggests that low and middle-income countries (LMICs) contribute to more than $80 \%$ of people who have mental disorders, and the proportions of people with mental illness who receive evidence-based treatments are likely to be even lower [5]. A relevant public health goal is to design and deliver a comprehensive intervention targeting the general populations in addition to individuals in clinical settings. But this effort requires identification of important risk factors for DD. Several studies [6-8] have attempted to identify factors independently associated with DD such as obesity, alcohol consumption, diabetes, etc., but these studies focused on a limited set of potential correlates of DD. That notwithstanding, the identification of important risk factor(s) is difficult. This complication could be attributed to the presence of correlated predictors [9] and is particularly the case in the context of binary outcome measures[10]. The presence of correlated predictors makes it difficult to 
isolate the contribution of each of the predictors to the total variation of the DD. Identifying the most important risk factor(s) from the holistic pool of critical correlates of DD could provide useful insight into designing a more targeted, efficient, and cost-effective country-specific interventions that could potentially address the problem of DD and this could lead to an improvement in their overall QoL. In addition to identifying important correlate of DD, this study further assessed the relationship between DD and QoL. Although some studies [11-15] have examined the association between DD and QoL, there remains a knowledge gap in terms of how these associations vary across different LMICs settings, particularly in the older adult population. A further gap in existing evidence is that most of these studies were based on data from a single country and were restricted to a few specific targeted geographic areas of the country or among disease-specific patients [16-18], making the findings not generalizable to the broader target population in LMICs. Application of modern statistical techniques, based on machine learning algorithms to nationally representative data in settings with varied population dynamics could potentially provide answers to these important questions. Using data from the World Health Organization (WHO) study on the global ageing and adult health (SAGE) which were collected with the same standardized data collection instrument on a similar target population (adults who are 50 years or older in six LMICs), we determined key risk factors for DD, and from among these, we identified the ones that contributed most to the prevalence of DD in six LMICs. We also estimated the effect of DD on QoL in these countries using Inverse Probability Weighted Poisson Regression Adjustment (IPWRA). The findings from this study will help fast-track the overall public health goal of improving the mental health status and QoL among the older adult population in LMICs.

\section{Methods}

\section{Study design and setting}

The SAGE was designed as a multi-wave panel study representative of the population aged 50 and older, with a smaller cohort of respondents aged 18-49 for comparative purposes but our study only involved older adults (50 years and older). The SAGE is a crossectional survey conducted in six LMICs. The objective of SAGE was to generate valid, reliable, and comparable information on a range of health and well-being outcomes of public health importance in adult and older adult populations [19]. SAGE wave 1 was conducted between 2007 and 2010 in six LMICs namely: China (2008-2010), Ghana (2008-2009), India (2007-2008), Mexico (2009-2010), the Russian Federation (2007-2010) and South Africa (20072008). The sampling design was a multi-stage stratified cluster sampling. The details of the sampling technique have been described elsewhere [19]. Briefly, each country was stratified into mutually exclusive strata. In the first stage of sampling, enumerations areas (EAs), referred to as clusters, were drawn from each stratum using probability proportional to size. In the second stage, households with at least one person aged 50 and older within each EA were randomly selected and interviewed. A smaller sample of adults aged 18-49 years were also selected. Ghana, India, Mexico, and Russia used the Wave 0 (20022004) sampling frame and reinterviewed at least 50 percent of the Wave 0 respondents. China used a new sampling frame based on a national health surveillance system, and South Africa did not collect follow-up interviews but used the same Wave 0 sampling frame. The average response rate for the 
individual in Wave is as follows: China (93\%), Ghana (81\%), India (68\%), Russian Federation (83\%), Mexico (53\%) and South Africa (75\%). The low response rate in Mexico could partly be attributed to the short time available for the fieldwork which did not allow sufficient time for multiple revisits if the respondent was not at home at the initial visit [20].

\section{Data collection procedures}

The field data collection was conducted in the six LMICs using a standardized survey instrument. The interviewers and their field supervisors were given a more rigorous and in-depth and training on the content of the questionnaire and translation protocols. The interviews were completed using either a computer-assisted personal interview, paper, and pencil format or both. The SAGE household questionnaire consists of a household roster and modules about the dwelling, income, transfers in and out of the household, assets, and expenditures. The individual questionnaire has modules on sociodemographic factors: age; marital status; education; ethnicity/background; religion; language spoken; area of residence; employment and education of parents; childhood residence, migration, health and its determinants, disability, work history, risk factors, chronic conditions, caregiving, subjective wellbeing and quality of life, health care utilization and health systems responsiveness, health functioning, chronic conditions, and health care utilization, anthropometric measurements (height, weight, waist and hip circumferences), blood pressure measures and a blood sample via finger prick, and performance tests including near and distant vision, a timed 4-m walk, grip strength, lung function, and cognition. The global positioning system was used to record the location coordinates of every household in the study. The household and the individual data were linked based on unique household and individual identifiers.

\section{Outcome measures}

The primary outcome of interest was the proportion of participants who self-reported higher QoL. The participants were asked to rate their overall QoL using five-point Likert scale response categories (very bad $=5$, bad $=4$, moderate $=3$, good $=2$ and very good $=1$ ). The very bad, bad, and moderate quality of life categories were merged as "lower/poorer quality of life" and were coded as 1, whereas the good and very good categories were merged as "higher quality of life" and were coded as 0 . This method of recategorizing the outcome as binary has been used elsewhere [21]. Although DD was the primary outcome variable of interest when investigating social determinants of $D D$, it was the main exposure of interest when we investigated the causal effect of DD on QoL. The presence of major depressive disorder was based on the International Classification of Diseases, Tenth Revision (ICD 10) diagnostic criteria, and was derived from an algorithm that took into account respondent reporting symptoms during the previous 12 months. Depression was diagnosed when the participants had a minimum of four depressive symptoms after admitting to experiencing at least one of these: depressed mood, loss of interest and enjoyment, and reduced energy leading to increased tiredness and diminished activity as listed in ICD-10 DCR (F32) and lasting most of the day and almost every day for at least two weeks. We included those who have previously been diagnosed with depression (either on treatment or not) to the prevalent cases obtained from the ICD10 diagnostic criteria. We considered covariates including sociodemographic factors, 
economic instability, education, social cohesion, neighborhood and adult built environment, chronic health conditions, healthcare factors, lifestyle factors, injuries, disability, oral health, and deaths in the household 24 months preceding the survey (Figure 1, and Appendix 1 of the supplementary material).

\section{Statistical analysis}

For each country, we summarized the background characteristics of participants using proportions for categorical variables and mean for continuous variables. To prepare the data for analyses, we pooled the six SAGE countries' data and the standard sampling weight was de-normalized. To de-normalize the adult sampling weight, we divided the standard sampling weight of the adults aged $50+$ by the sampling fraction of adults aged $50+$. The sampling fraction of adults aged $50+$ is the ratio of the total number of adults interviewed in the survey over the total number of adults aged $50+$ in the country at the time of the survey. The de-normalization of the sampling weight became necessary because we studied different countries with different population sizes at different time points of the survey. Besides, de-normalization makes it possible to generate an unbiased estimate and draw a valid conclusion of the true impact of DD on QoL in the six LMICs.

The total number of adults aged 50+ interviewed within this period was 35,164 and distributed as follows: China-13,408; Ghana-4,305; India-7,108; Mexico-2,309; Russian Federation-3,763; and South Africa-3,842. Using items response theory (rating scale models), we constructed latent variables such as mobility, self-care, pain and discomfort, cognition, interpersonal activity, sleep and energy, and vision based on some observed characteristics. The Rao-Scott chi-square test (a design-adjusted version of the Pearson chi-square test) and a design-adjusted one-way analysis of variance were used to test the relationship between each covariate and how they vary among the six countries.

To identify factors independently associated with the prevalence of DD, we used the double selection Least Absolute Shrinkage and Selection Operator Poisson regression model (DSLASSOPM). This model was appropriate because it obtained unbiased and efficient estimates by addressing the problems of multicollinearity that arose from a large number of highly correlated predictor variables. Based on the literature and the availability of data or variables in the secondary datasets, we identified 58 variables $a$ priori and were grouped into nine main domains namely: sociodemographic, educational, economic, neighborhood, lifestyle, social cohesion, healthcare, chronic conditions, and injuries/deaths in the last 12 months preceding the survey. To estimate the effect of a particular domain on DD, we adjust for the remaining eight domains. We assumed that the variables selected from DSLASSOPM are the only known independent predictors of DD and therefore applied weighted dominance regression analysis [22] to determine the relative importance of these predictors. Dominance analysis is an ensemble method that ranks the predictors in terms of importance by aggregating results across multiple models. The general dominance statistics were derived as a weighted average marginal/incremental contribution to the overall fit statistic that a predictor variable makes across all models in which the predictor variable was included. 
To quantify the effect of DD on QoL, we used inverse probability weighting Poisson regression adjustment model (IPWRA). One of the important characteristics of IPWRA is double robustness (i.e., even if one of the models (exposure or outcome) is misspecified, the estimator is still consistent). To achieve the goal of reducing bias in the differences in covariate distributions between subjects with DD and those without DD, we chose well-matched samples of the older adults with DD and control groups (individuals without DD). The reduction in bias in terms of covariate imbalance between the two groups increases the likelihood of estimating the causal effect of DD on QoL. To satisfy the assumption of ignorable treatment assignment, we included in the matching procedure, all variables are known to be related to both DD and QoL $[23,24]$. This assumption states that in the absence of the covariates studied, including DD, there are no unobserved factors that could influence the QoL.

Meta-analysis was used to obtain a single estimate of the effect of DD on QoL from the six LMICs. We achieved this by computing a weighted average of the studies' individual estimates of DD effect on QoL. Random-effects meta-analysis models using R DerSimonian and NJCct Laird [25] estimation of the random-effects variance was used. This approach incorporates an estimate of between-study variation (heterogeneity) in the weighting. We further applied the Knapp-Hartung adjustment to the overall effect size standard error. All analyses were performed in Stata 16 MP (StataCorp, College Station, Texas, USA) and all estimates were adjusted for complex survey design characteristics (sampling weight, stratification, and clustering).

\section{Results}

\section{Characteristics of the study population}

A total of 34,735 adults with a mean age of 62.2 years, and approximately $1: 1$ male to female ratio were involved in this study (Table 1). Approximately $58 \%$ of all older adults lived in the rural areas, and the proportional rural inhabitants were higher in the two African countries compared to the remaining countries (Ghana $=70.6 \%$, South Africa $=59.4 \%$, Table 1 ). Among the six LMICs, Ghana recorded the lowest proportion of households with improved toilet facilities (41.5\%; Table 1). The detailed percentage distribution of the sociodemographic/economic factors in the six countries can be found in Table 1. The results from the Rao-Scott Chi-square test of independence showed that except socioeconomic status, there was a statistically significant association between all the other sociodemographic/economic factors, and country of origin $(p<0.05$, Table 1$)$.

Table 1: Characteristics of population aged 50 years and above in SAGE countries. 


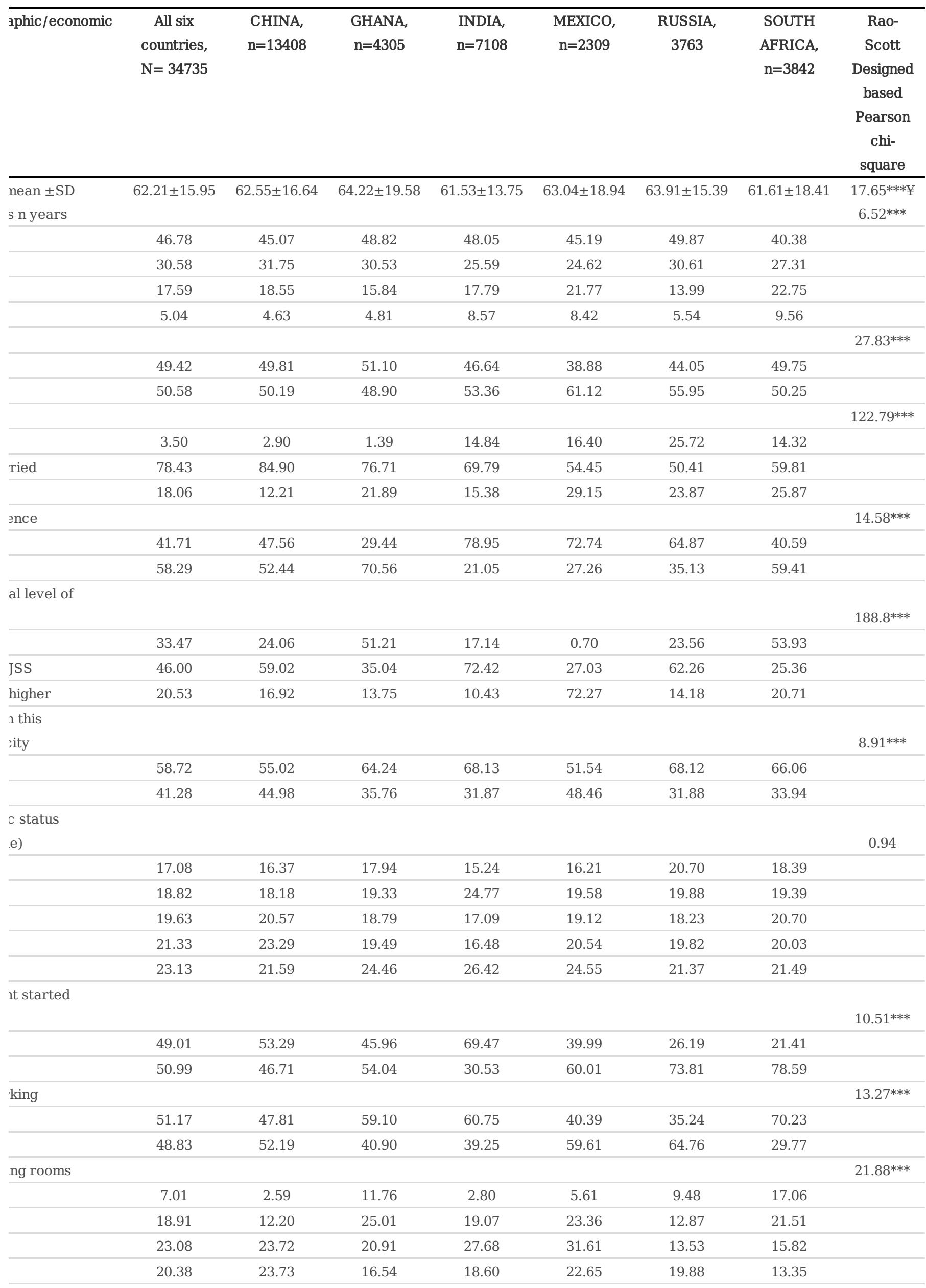




\begin{tabular}{|c|c|c|c|c|c|c|c|c|}
\hline & 30.62 & 37.76 & 25.77 & 31.86 & 16.76 & 44.24 & 32.25 & \\
\hline r source & & & & & & & & $12.31^{* * *}$ \\
\hline & 7.03 & 3.61 & 11.35 & 0.71 & 2.96 & 5.22 & 15.90 & \\
\hline facility & & & & & & & & $281.42^{* * *}$ \\
\hline & 31.10 & 7.56 & 58.51 & 2.01 & 15.07 & 17.08 & 34.12 & \\
\hline
\end{tabular}

$¥$ : Estimates from One Way Analysis of variance but we adjusted for survey design characteristics (weighting, clustering, and stratification). P-value notation: ***:p $<0.001, * * \mathrm{p}<0.01, * * \mathrm{p}<0.05$.

\section{Prevalence of depressive disorders, poor quality of life and life satisfaction}

The overall prevalence of DD among the adult population was approximately $10.9 \%$ (95\% Cl: 9.6-12.3; Table 2). Ghana recorded the highest prevalence of DD (Prevalence; Prev=20.3\%; 95\%Cl: 18.3-22.4) while China had the lowest prevalence of 2.3\% (95\% Cl:1.9-2.8; Table 2). The prevalence of poor QoL in the six countries was $65.5 \%$ (95\% Cl: 65.5-67.1; Table 2). Older adults from the Russian Federation recorded the poorest QoL with an estimated prevalence of 74.3\% (95\% Cl: 67.94 -79.80; Table 2).

Table 2: Prevalence of depressive disorders, poor quality of life and life satisfaction

\begin{tabular}{lllllllll}
\hline & $\begin{array}{c}\text { All six } \\
\text { countries }\end{array}$ & CHINA & GHANA & INDIA & MEXICO & RUSSIA & $\begin{array}{c}\text { SOUTH } \\
\text { AFRICA }\end{array}$ & $\begin{array}{c}\text { Rao-Scott Designed based } \\
\text { Pearson chi-square }\end{array}$ \\
\hline re Disorders: & 10.86 & 2.25 & 20.25 & 17.62 & 8.59 & 5.62 & 9.03 & \\
:I] & {$[9.57-$} & {$[1.85-$} & {$[18.25-$} & {$[12.41-$} & {$[6.64-$} & {$[4.59-$} & {$[7.63-$} & $267.8^{* * *}$ \\
& $12.30]$ & $2.75]$ & $22.41]$ & $24.41]$ & $11.04]$ & $6.87]$ & $10.66]$ & \\
lity of life: \% & 65.47 & 64.97 & 69.79 & 64.16 & 43.46 & 74.32 & 67.22 & \\
& {$[63.76-$} & {$[62.56-$} & {$[67.64-$} & {$[61.50-$} & {$[38.23-$} & {$[67.94$} & {$[63.62-$} & \\
& $67.14]$ & $67.3]$ & $71.86]$ & $66.74]$ & $48.83]$ & $-79.80]$ & $70.63]$ & $4.65^{* *}$ \\
\hline
\end{tabular}

P-value notation: $* \mathrm{p}<0.05, * *: \mathrm{p}<0.01, * * *: \mathrm{p}<0.001$.

\section{Risk factors for depressive disorders}

The detailed results on how each risk factor is associated with DD in each of the six countries can be found in (Appendix 1-appendix 5). The risk factors for DD were generally country-specific. However, Asthma was the common risk factor for DD across all six LMICs. In Ghana, the prevalence of DD among older adults who have been diagnosed with Asthma or have experienced symptoms of Asthma in the 12 months preceding the survey was 14 times that among those without Asthma or asymptomatic of Asthma (Adjusted Prevalence Ratio (aPR) $=14.46,95 \%$ Cl: 10.47-19.97, $p<0.001$; Table 3). Similarly, it was 14 times in South Africa (aPR=14.6, 95\% Cl: 8.18-26.14, $p<0.00)$ but in Mexico, it was 4 times $(a P R=4.39$, 95\% Cl: 3.00-6.42, $\mathrm{p}<0.001)$ and in China (aPR=5.99, 95\% Cl: 4.32-8.31, $\mathrm{p}<0.001$; Table 3 ) and Russia (aPR=5.9, 95\% Cl: 3.9-9.0, $p<0.001$; Table 3), it was 6 times. In India, it was 5 times (aPR=5.1, 95\% Cl: 4.3$6.0, p<0.001$; Table 3). 
Table 3: Risk factors for depressive disorders.

\begin{tabular}{|c|c|c|c|c|c|c|}
\hline & CHINA & GHANA & INDIA & MEXICO & RUSSIA & $\begin{array}{l}\text { SOUTH } \\
\text { AFRICA } \\
\end{array}$ \\
\hline Chronic conditions & aPR[95\% CI] & aPR $[95 \% \mathrm{CI}]$ & aPR $[95 \% \mathrm{CI}]$ & aPR $[95 \% \mathrm{CI}]$ & aPR $[95 \% \mathrm{CI}]$ & aPR[95\% CI] \\
\hline Presence of stroke or symptoms (yes) & $\begin{array}{l}1.05[0.69- \\
1.60]\end{array}$ & $\begin{array}{c}1.37 *[1.03- \\
1.83]\end{array}$ & $\begin{array}{l}0.98[0.80- \\
1.21]\end{array}$ & $\begin{array}{c}1.45^{*}[1.01- \\
2.09]\end{array}$ & $\begin{array}{c}1.37 *[1.03- \\
1.81]\end{array}$ & $\begin{array}{l}0.56[0.27- \\
1.30]\end{array}$ \\
\hline Presence of angina or symptoms (yes) & $\begin{array}{l}1.14[0.85- \\
1.54]\end{array}$ & $\begin{array}{l}0.90[0.71- \\
1.13]\end{array}$ & $\begin{array}{l}0.92[0.82- \\
1.04]\end{array}$ & $\begin{array}{c}1.22[0.93- \\
1.63]\end{array}$ & $\begin{array}{l}1.11[0.85- \\
1.46]\end{array}$ & $\begin{array}{l}1.24[0.68- \\
2.27]\end{array}$ \\
\hline $\begin{array}{l}\text { Diagnosed with diabetes or } \\
\text { symptoms (yes) }\end{array}$ & $\begin{array}{c}0.66[0.39- \\
1.12]\end{array}$ & $\begin{array}{l}0.92[0.67- \\
1.27]\end{array}$ & $\begin{array}{c}1.08[0.87- \\
1.35]\end{array}$ & $\begin{array}{c}1.33[0.97- \\
1.83]\end{array}$ & $\begin{array}{l}1.09[0.81- \\
1.48]\end{array}$ & $\begin{array}{c}0.65[0.36- \\
1.21]\end{array}$ \\
\hline $\begin{array}{l}\text { Diagnosed with lung disease or } \\
\text { symptoms (yes) }\end{array}$ & $\begin{array}{l}0.97[0.72- \\
1.31]\end{array}$ & $\begin{array}{l}1.21[0.88- \\
1.67]\end{array}$ & $\begin{array}{l}0.89[0.79- \\
1.01]\end{array}$ & $\begin{array}{l}0.90[0.69- \\
1.18]\end{array}$ & $\begin{array}{l}0.98[0.78- \\
1.24]\end{array}$ & $\begin{array}{l}1.32[0.64- \\
2.75]\end{array}$ \\
\hline $\begin{array}{l}\text { Diagnosed with hypertension or } \\
\text { symptomsv(yes) }\end{array}$ & $\begin{array}{c}0.91 \\
{[0.67-1.24]}\end{array}$ & $\begin{array}{c}0.99 \\
{[0.80-1.22]}\end{array}$ & $\begin{array}{c}1.04 \\
{[0.90-1.21]}\end{array}$ & $\begin{array}{c}1.01 \\
{[0.76-1.34]}\end{array}$ & $\begin{array}{c}1.04[0.80- \\
1.34]\end{array}$ & $\begin{array}{c}2.99 * * * \\
{[1.81-4.92]}\end{array}$ \\
\hline Diagnosed with cataract (yes) & $\begin{array}{c}0.97 \\
{[0.74-1.28]}\end{array}$ & $\begin{array}{c}1.10 \\
{[0.94-1.29]}\end{array}$ & $\begin{array}{c}1.23^{* *} \\
{[1.06-1.43]}\end{array}$ & $\begin{array}{c}1.56^{* *} \\
{[1.11-2.20]}\end{array}$ & $\begin{array}{c}1.21 \\
{[0.94-1.55]}\end{array}$ & $\begin{array}{c}0.84 \\
{[0.43-1.65]}\end{array}$ \\
\hline Current memory (Good) & $\begin{array}{c}0.81[0.50- \\
1.29]\end{array}$ & $\begin{array}{c}1.05[0.83- \\
1.34]\end{array}$ & $\begin{array}{c}1.08[0.95- \\
1.23]\end{array}$ & $\begin{array}{c}1.34 \text { [0.97- } \\
1.83]\end{array}$ & $\begin{array}{c}0.89[0.94- \\
1.55]\end{array}$ & $\begin{array}{c}1.08[0.63- \\
1.87]\end{array}$ \\
\hline Oral health (Good) & $\begin{array}{c}0.96[0.70- \\
1.35]\end{array}$ & $\begin{array}{c}0.98[0.73- \\
1.30]\end{array}$ & $\begin{array}{c}0.99[0.88- \\
1.12]\end{array}$ & $\begin{array}{c}1.26[0.95- \\
1.67]\end{array}$ & $\begin{array}{c}1.14[0.64- \\
1.24]\end{array}$ & $\begin{array}{c}1.51[0.67- \\
3.39]\end{array}$ \\
\hline Asthma or related symptoms (yes) & $\begin{array}{c}5.99 * * * \\
{[4.32-8.31]}\end{array}$ & $\begin{array}{c}14.46^{* * *} \\
{[10.47-19.97]}\end{array}$ & $\begin{array}{c}5.09 * * * \\
{[4.28-6.01]}\end{array}$ & $\begin{array}{c}4.39 * * * \\
{[3.00-6.42]}\end{array}$ & $\begin{array}{c}5.92 * * * \\
{[3.91-8.98]}\end{array}$ & $\begin{array}{c}14.6^{* * *} \\
{[8.18-26.14]}\end{array}$ \\
\hline Presence of arthritis or symptoms & $\begin{array}{c}1.47 * *[1.10- \\
1.96]\end{array}$ & $\begin{array}{c}1.16[0.91- \\
1.48]\end{array}$ & $\begin{array}{c}1.37 * * *[1.21- \\
1.56]\end{array}$ & $\begin{array}{c}0.92[0.67- \\
1.25]\end{array}$ & $\begin{array}{c}0.70 *[0.53- \\
0.92]\end{array}$ & $\begin{array}{c}1.71[1.05- \\
2.80] \\
\end{array}$ \\
\hline
\end{tabular}

P-value notation: ${ }^{* * *} \mathrm{p}<0.001,{ }^{* *} \mathrm{p}<0.01, * \mathrm{p}<0.05$. Abbreviation-aPR: Adjusted Prevalence Ratio, Note: The prevalence ratios were obtained from the double selection Least Absolute Shrinkage and Selection Operator (Lasso) Poisson regression model adjusted for sociodemographic factors, economic instability, education, social cohesion, neighborhood and adult built environment, healthcare factors, lifestyle factors, injuries, disability, oral health, and deaths in the household 24 months preceding the survey.

\section{The relative importance of risk factors for depressive disorders}

The results from the weighted dominance analysis showed that having been diagnosed with Asthma or having symptoms of Asthma in the 12 months preceding the survey was the most important risk factor for DD across the six countries. For example, in China, Asthma alone contributed approximately $53 \%$ of the share of the coefficient of variation (Weighted Standardized Dominance Statistic; WSDS $=0.53$; Table 4). In Ghana, Asthma contributed approximately $74 \%$ of the share of the coefficient of variation (WSDS $=0.74$; Table 4). In India, Mexico, the Russian Federation, and South Africa, Asthma or symptoms of Asthma contributed approximately $59 \%, 50 \%, 63 \%$ and $83 \%$ of the share of the coefficient of variation, respectively (Table 4 ). 
Table 4: Relative predictor importance of depressive disorders in six low and middle- income countries.

\begin{tabular}{|c|c|c|c|c|c|c|c|c|c|c|c|}
\hline China & & Ghana & & India & & Mexico & & $\begin{array}{c}\text { Russian } \\
\text { Federation }\end{array}$ & & $\begin{array}{l}\text { South } \\
\text { Africa }\end{array}$ & \\
\hline $\begin{array}{l}\text { Key predictors } \\
\text { of DD obtained } \\
\text { from double } \\
\text { selection Lasso }\end{array}$ & $\begin{array}{l}\text { WSDS } \\
\text { Statistic } \\
\text { (rank) }\end{array}$ & $\begin{array}{l}\text { Key } \\
\text { predictors } \\
\text { of DD } \\
\text { obtained } \\
\text { from double } \\
\text { selection } \\
\text { Lasso }\end{array}$ & $\begin{array}{l}\text { WSDS } \\
\text { Statistic } \\
\text { (rank) }\end{array}$ & $\begin{array}{l}\text { Key } \\
\text { predictors of } \\
\text { DD obtained } \\
\text { from double } \\
\text { selection } \\
\text { Lasso }\end{array}$ & $\begin{array}{l}\text { WSDS } \\
\text { Statistic } \\
\text { (rank) }\end{array}$ & $\begin{array}{l}\text { Key } \\
\text { predictors } \\
\text { of DD } \\
\text { obtained } \\
\text { from double } \\
\text { selection } \\
\text { Lasso }\end{array}$ & $\begin{array}{l}\text { WSDS } \\
\text { Statistic } \\
\text { (rank) }\end{array}$ & $\begin{array}{l}\text { Key } \\
\text { predictors } \\
\text { of DD } \\
\text { obtained } \\
\text { from double } \\
\text { selection } \\
\text { Lasso }\end{array}$ & $\begin{array}{l}\text { WSDS } \\
\text { Statistic } \\
\text { (rank) }\end{array}$ & $\begin{array}{l}\text { Key } \\
\text { predictors } \\
\text { of DD } \\
\text { obtained } \\
\text { from } \\
\text { double } \\
\text { selection } \\
\text { Lasso }\end{array}$ & $\begin{array}{l}\text { WSDS } \\
\text { Statistic } \\
\text { (rank) }\end{array}$ \\
\hline Asthma & 0.5334 & Asthma & 0.7365 & Asthma & 0.5873 & Asthma & 0.5016 & Asthma & 0.6281 & Asthma & 0.8329 \\
\hline $\begin{array}{l}\quad \text { (1) } \\
\text { Sleep and } \\
\text { energy }\end{array}$ & $\begin{array}{c}(1) \\
0.1479 \\
(2)\end{array}$ & $\begin{array}{l}\quad \text { (1) } \\
\text { Sleep and } \\
\text { energy }\end{array}$ & $\begin{array}{c}(1) \\
0.1506 \\
(2)\end{array}$ & $\begin{array}{l}\quad \text { (1) } \\
\text { Pain and } \\
\text { discomfort }\end{array}$ & $\begin{array}{c}(1) \\
0.0850 \\
(2)\end{array}$ & $\begin{array}{l}\text { (1) } \\
\text { Sex }\end{array}$ & $\begin{array}{c}\text { (1) } \\
0.2437 \\
\text { (2) }\end{array}$ & $\begin{array}{l}\quad \text { (1) } \\
\text { Sleep and } \\
\text { energy }\end{array}$ & $\begin{array}{c}(1) \\
0.1168 \\
(2)\end{array}$ & $\begin{array}{c}\text { (1) } \\
\text { Hypertensi } \\
\text { on }\end{array}$ & $\begin{array}{c}(1) \\
0.0645 \\
(2)\end{array}$ \\
\hline $\begin{array}{l}\text { Current health } \\
\text { condition }\end{array}$ & $\begin{array}{c}0.1060 \\
\text { (3) }\end{array}$ & Self-care & $\begin{array}{c}0.0324 \\
(3)\end{array}$ & Arthritis & $\begin{array}{c}0.0681 \\
\text { (3) }\end{array}$ & $\begin{array}{l}\text { Sleep and } \\
\text { energy }\end{array}$ & $\begin{array}{c}0.1464 \\
\text { (3) }\end{array}$ & Self-care & $\begin{array}{c}0.1053 \\
(3)\end{array}$ & Cognition & $\begin{array}{c}0.0354 \\
\text { (3) }\end{array}$ \\
\hline $\begin{array}{l}\text { Interpersonal } \\
\text { activities }\end{array}$ & $\begin{array}{c}0.0908 \\
(4)\end{array}$ & $\begin{array}{l}\text { Social } \\
\text { cohesion }\end{array}$ & $\begin{array}{c}0.0201 \\
\text { (4) }\end{array}$ & Mobility & $\begin{array}{c}0.0519 \\
(4)\end{array}$ & Cataract & $\begin{array}{c}0.0441 \\
(4)\end{array}$ & Sex & $\begin{array}{c}0.0896 \\
(4)\end{array}$ & $\begin{array}{c}\text { Age of } \\
\text { responden } \\
t\end{array}$ & $\begin{array}{c}0.0274 \\
(4)\end{array}$ \\
\hline Arthritis & $\begin{array}{l}0.0692 \\
(5)\end{array}$ & Fruits & $\begin{array}{c}0.0176 \\
(5)\end{array}$ & Self-care & $\begin{array}{c}0.0485 \\
(5)\end{array}$ & Stroke & $\begin{array}{l}0.0288 \\
(5)\end{array}$ & Age & $\begin{array}{l}0.0180 \\
(5)\end{array}$ & $\begin{array}{l}\text { Currently } \\
\text { working }\end{array}$ & $\begin{array}{c}0.0142 \\
(5)\end{array}$ \\
\hline $\begin{array}{l}\text { Safety in the } \\
\text { neighborhood }\end{array}$ & $\begin{array}{c}0.0234 \\
(6)\end{array}$ & Stroke & $\begin{array}{c}0.0139 \\
(6)\end{array}$ & Cognition & $\begin{array}{c}0.0442 \\
(6)\end{array}$ & $\begin{array}{c}\text { Vegetable } \\
\text { intake per } \\
\text { day }\end{array}$ & $\begin{array}{c}0.0157 \\
(6)\end{array}$ & Vision & $\begin{array}{c}0.0136 \\
(6)\end{array}$ & $\begin{array}{c}\text { Vegetable } \\
\text { intake per } \\
\text { day }\end{array}$ & $\begin{array}{c}0.0095 \\
\text { (6) }\end{array}$ \\
\hline Injuries & $\begin{array}{c}0.0156 \\
(7)\end{array}$ & Sports & $\begin{array}{c}0.0131 \\
(7)\end{array}$ & Cataract & $\begin{array}{c}0.0418 \\
(7)\end{array}$ & $\begin{array}{l}\text { Safety in the } \\
\text { neighborho } \\
\text { od }\end{array}$ & $\begin{array}{c}0.0126 \\
(7)\end{array}$ & Arthritis & $\begin{array}{c}0.0102 \\
(7)\end{array}$ & $\begin{array}{l}\text { Always } \\
\text { lived in } \\
\text { this } \\
\text { village/tow } \\
\text { n/city }\end{array}$ & $\begin{array}{c}0.0095 \\
(7)\end{array}$ \\
\hline $\begin{array}{l}\text { Age of } \\
\text { respondent }\end{array}$ & $\begin{array}{c}0.0025 \\
(8)\end{array}$ & $\begin{array}{l}\text { Interperson } \\
\text { al activities }\end{array}$ & $\begin{array}{c}0.0068 \\
(8)\end{array}$ & $\begin{array}{l}\text { Improve } \\
\text { toilet facility }\end{array}$ & $\begin{array}{c}0.0149 \\
(8)\end{array}$ & $\begin{array}{l}\text { Improved } \\
\text { water } \\
\text { source }\end{array}$ & $\begin{array}{c}0.0039 \\
(8)\end{array}$ & $\begin{array}{l}\text { Victim of a } \\
\text { crime }\end{array}$ & $\begin{array}{c}0.0098 \\
(8)\end{array}$ & $\begin{array}{l}\text { Tobacco } \\
\text { use }\end{array}$ & $\begin{array}{c}0.0053 \\
(8)\end{array}$ \\
\hline \multirow[t]{10}{*}{$\begin{array}{l}\text { Receive } \\
\text { support from } \\
\text { community }\end{array}$} & $\begin{array}{c}0.0007 \\
\text { (9) }\end{array}$ & $\begin{array}{l}\text { Health } \\
\text { service } \\
\text { utilization }\end{array}$ & $\begin{array}{c}0.0038 \\
(9)\end{array}$ & $\begin{array}{l}\text { Fathers } \\
\text { education } \\
\text { level }\end{array}$ & $\begin{array}{c}0.0138 \\
(9)\end{array}$ & $\begin{array}{l}\text { Marital } \\
\text { status }\end{array}$ & $\begin{array}{c}0.0032 \\
\text { (9) }\end{array}$ & Stroke & $\begin{array}{c}0.0060 \\
(9)\end{array}$ & $\begin{array}{l}\text { Place of } \\
\text { residence }\end{array}$ & $\begin{array}{l}0.0015 \\
\text { (9) }\end{array}$ \\
\hline & & Number of & 0.0028 & Social & 0.0120 & & & Alcohol & 0.0022 & & \\
\hline & & $\begin{array}{l}\text { living rooms } \\
\text { Mothers }\end{array}$ & $\begin{array}{c}(10) \\
0.0015\end{array}$ & $\begin{array}{l}\text { cohesion } \\
\text { Injury }\end{array}$ & (10) & & & $\begin{array}{l}\text { intake } \\
\text { Father's }\end{array}$ & $\begin{array}{c}(10) \\
0.0003\end{array}$ & & \\
\hline & & education & (11) & Injury & (11) & & & $\begin{array}{l}\text { educational } \\
\text { level }\end{array}$ & (11) & & \\
\hline & & $\begin{array}{l}\text { Improved } \\
\text { toilet facility }\end{array}$ & $\begin{array}{c}0.0009 \\
(12)\end{array}$ & $\begin{array}{l}\text { Deaths in } \\
\text { household in } \\
\text { the last } 24\end{array}$ & $\begin{array}{c}0.0070 \\
(12)\end{array}$ & & & & & & \\
\hline & & & & $\begin{array}{l}\text { months } \\
\text { Provide } \\
\text { support to } \\
\text { community }\end{array}$ & $\begin{array}{c}0.0055 \\
(13)\end{array}$ & & & & & & \\
\hline & & & & $\begin{array}{l}\text { Safety in the } \\
\text { neighborhood }\end{array}$ & $\begin{array}{c}0.0045 \\
(14)\end{array}$ & & & & & & \\
\hline & & & & $\begin{array}{l}\text { Currently } \\
\text { working }\end{array}$ & $\begin{array}{c}0.0034 \\
(15)\end{array}$ & & & & & & \\
\hline & & & & Mothers & 0.0010 & & & & & & \\
\hline & & & & $\begin{array}{c}\text { educational } \\
\text { level }\end{array}$ & (16) & & & & & & \\
\hline
\end{tabular}

Abbreviations: DD: Depressive Disorders; WSDS: Weighted Standardized Dominance Statistic

\section{Effect of depressive disorders on quality of life}

Generally, there was evidence of $8 \%$ increase in poor QoL due to the presence of DD (Pooled estimate $=0.08 ; 95 \%$ Cl: $6.0-12, p<0.001$, Table 5]. Specifically, in China, there was evidence of $12 \%$ increase in poor QoL due to the presence of DD (prevalence difference $(P D)=0.12 ; 95 \% \mathrm{Cl}: 0.07-0.18, p<0.001$, Table 5 ). In India ( $P D=0.08 ; 95 \% \mathrm{Cl}: 0.04-0.13, \mathrm{p}<0.01)$ and Russian Federation ( $\mathrm{PD}=0.08 ; 95 \% \mathrm{Cl}: 0.01-0.15, \mathrm{p}<0.01)$, there was evidence of $8 \%$ increase in poor QoL (Table 5). Although there was some increase in poor QoL in Mexico, Ghana, and South Africa due to DD, the increase was not statistically significant (Table 4).

Table 5: Effect of depressive disorders on the quality of life

\begin{tabular}{lc}
\hline Country & Poor quality of life \\
\hline China & Impact estimate $[95 \% \mathrm{Cl}]$ \\
Ghana & $0.12^{* * * *}[0.07,0.18]$ \\
India & $0.00[-0.06,0.06]$ \\
Mexico & $0.08^{* *}[0.04,0.13]$ \\
Russian Federation & $0.14[-0.01,0.29]$ \\
South Africa & $0.08^{* *}[0.01,0.15]$ \\
Pooled Estimate from the random effect meta-analvsis & $0.07[-0.01,0.15]$ \\
\hline P-value notation: $* * * p<0.001, * * p<0.01, * 00.05$, CI: Confiden & $0.08 *[0.06 .0 .2]$
\end{tabular}

P-value notation: ${ }^{* * *} \mathrm{p}<0.001,{ }^{* *} \mathrm{p}<0.01,{ }^{*} \mathrm{p}<0.05$, CI: Confidence Interval 


\section{Discussion}

Generally, studies from LMICs have identified several risk factors of DD, but the majority of the studies on DD focused on very limited correlates of DD. These studies have shown that the risk factors for DD vary across countries and is dependent largely on the target population. This study identified the most common and most important risk factor for DD in six LMICs and estimated the effect o DD on QoL in six LMICs among older adults. We found that, although the risk factors were country-specific, having been diagnosed with Asthma or having symptoms of Asthma in the last 12 months preceding the survey was the common and the most dominant risk factor for DD across the six SAGE countries. Our finding is consistent with the results of a previous study that systematically reviewed studies between the periods of 1966-1999 [26]. We found that depressive symptoms are more common in asthma patients than in the general population and even more common than in some other general medical conditions. In another study, BMJJ Kuehn [27] found that individuals with asthma appeared to have about a twofold higher risk of having DD, and in adults with asthma, DD problems are also associated with poor asthma control [28], but the biological mechanism underlying the relationship between Asthma and DD is not well understood [29]. In fact, the relationship between Ashma and DD can be bidirectional as indicated by a few cases in the literature and thus, pointing to the possibility that the two complex chronic illnesses could share common pathophysiological pathways and susceptibility genes [30]. The first multi-national study of the relationship between asthma and mental disorders in 17 countries confirms that a range of common mental disorders occurs with greater frequency among persons with asthma [31]. Again, AN Ortega, JM Feldman, G Canino, K Steinman, MJSp Alegría and p epidemiology [32] further supported our findings when they studied 2,554 American Latinos and found that among patients diagnosed with cardiovascular disease, diabetes, and asthma, only patients with asthma had an increased risk of depressive disorder. The comorbidity between asthma and the affective traits may, in part, be due to shared genetic influences between asthma and depression [33]. Thus, our study largely agrees with the findings from previous studies and even provides more convincing evidence on the need to understand the biological mechanism that explains the relationship between Asthma and DD for better treatment outcomes [34].

We also found that adults with DD have poor QoL compared to those without DD in China, India, and the Russian Federation. The overall effect from the meta-analysis showed a statistically significant effect of DD on QoL. This finding is consistent with what was found in a systematic review conducted by $\mathrm{H}$ Sivertsen, GH Bjørkløf, K Engedal, G Selbæk and A-S Helvik [35], and a prospective cohort study in the case of LK Hasche, N Morrow-Howell and EK Proctor [36]. The former showed that an increase in DD among older persons had poorer global and generic health-related QoL than non-depressed individuals independent of the instrument used in measuring QoL. DD significantly impairs the proper functioning in a number of areas, including work functioning, social functioning, and health in general [37]. Although the biological mechanism that explains exactly how DD influences QoL may not be known, some authors are of the view that sleep quality may act as a mediator between depression and the QoL in older adults and evidence suggests that there is a close link between impaired sleep and aging-related cognitive decline[38, 39]. It is possible that those older adults on some treatments such as pharmacotherapy 
and/or psychotherapy might have enhanced their QoL. A Farabaugh, L Fisher, M Nyer, D Holt, M Cohen, L Baer, BG Shapero, I Huz, A Cardoos and MJ Fava, 27, 2 [40] found little evidence to support the potential benefit of these treatment options. Anecdotal evidence, however, shows that psychotherapy is a preferred means of addressing QoL since that directly targets the overall well-being, unlike psychopharmacology that indirectly targets QoL by focussing on symptoms. Future studies to understand the alternative pathway for this relationship is an important consideration. Meanwhile, having a more targeted intervention for adult Asthma patients with DD could potentially improve their QoL.

\section{Strengths And Limitations}

Our study has some strengths worth mentioning. The use of a multi-nationally representative data that originate from the same data collection instrument makes our findings generalizable to the entire adult population in the six LMICs. The use of a standardized tool to measure the same outcomes of interest and covariates ensures that our results are generalizable to LMICs. We have applied a more rigorous statistical technique to assess several variables that explain the dynamics of $\mathrm{DD}$, and we have identified the single most important predictor of DD based on the variables that were studied. It remains the only study that has identified common and most important predictor of DD in six LMICs. To our knowledge, this is the only study that provided a wide-ranging and most exhaustive description of risk factors for DD among older adults in SAGE countries. The scope of the number of risk factors that were studied reduces the likelihood of omitted variable bias. Not much has been done in the application of inverse probability weighting Poisson regression adjustment technique to quantify the effect of DD on QoL in each country using data that originate from an observational study. To reduce bias in our effect estimates, we highlighted the need to apply doubly robust procedures in assessing key risk factors on the health outcome of interest, especially when the data originate from cross-sectional study design instead of the more preferred and robust experimental study design. That notwithstanding, the study has some limitations too. Although our multivariable analysis adjusted for several confounders and we conducted our matching procedure based on these observed confounders, we anticipate that there could be some unmeasured covariates that are common risk factors for DD and QoL. Future studies could evaluate the actual contribution of Asthma in explaining the dynamics of DD controlling for the confounding effect of genetic and other biological factors using a more rigorous prospective cohort study design. The use of findings from cross-sectional study design to infer causality should be interpreted with caution, although a more rigorous statistical procedure was employed. This is because inferring causality from crossectional data could lead to reverse causality bias. For instance, Asthma was found to be associated with an increase in the prevalence of DD, but we do not know whether the person had Asthma before being diagnosed with DD or vice versa.

\section{Conclusions}

Although different factors could explain the prevalence of DD among older adults in the six LMICs, it was evident that adults who have been diagnosed with Asthma or are experiencing symptoms of Asthma in 
the last 12 months preceding the survey were at a higher risk of DD. To improve the treatment outcomes of patients with DD and Asthma, physicians and other health personnel treating older adults with Asthma should understand that those adults are at a greater risk of DD and poor QoL and that any proposed treatment regimen for asthmatic patents should include the diagnosis and treatment of DD. The findings emphasized the need to improve access to mental healthcare.

\section{Abbreviations}

DD: Depressive Disorders

LMICs: Low and middle-income countries

QoL: Quality of Life

IPWRA: Inverse Probability Weighted Poisson Regression Adjustment

LASSO: Least Absolute Shrinkage and Selection Operator

WHO: World Health Organization

\section{Declarations}

\section{Ethics approval and consent to participate}

The study used secondary data sets that are publicly available

\section{Consent for publication}

Not applicable

\section{Availability of data and materials}

SAGE is committed to the public release of study instruments, protocols and meta- and micro-data: access is provided upon completion of a Users Agreement available through WHO's SAGE website (www.who.int/healthinfo/systems/sage) and WHO's archive using the National Data Archive application (http://apps.who.int/healthinfo/systems/surveydata).

\section{Competing interests}

The authors declare that they have no competing interests

\section{Funding}

None. This research did not receive any specific grant from funding agencies in the public, commercial, or not-for-profit sectors. 
DD conceived the idea, conducted the statistical analysis, and writing of the first draft of the manuscript. SB reviewed the statistical methods. DD, GI, EA, SAA, SB, AEY, contributed to the literature review, discussion of the findings, interpretation, and revision of the manuscript drafts, supported the data validation and data management. All authors have access to the data, read, and approved the final manuscript.

\section{Acknowledgements}

We are grateful to the WHO SAGE team and all the respondents that participated in the SAGE study.

\section{References}

1. Wells KB, Stewart A, Hays RD, Burnam MA, Rogers W, Daniels M, Berry S, Greenfield S, Ware JJJ: The functioning and well-being of depressed patients: results from the Medical Outcomes Study. 1989, 262(7):914-919.

2. Bartels MJBg: Genetics of wellbeing and its components satisfaction with life, happiness, and quality of life: A review and meta-analysis of heritability studies. 2015, 45(2):137-156.

3. Snyder HRJPb: Major depressive disorder is associated with broad impairments on neuropsychological measures of executive function: a meta-analysis and review. 2013, 139(1):81.

4. James SL, Abate D, Abate KH, Abay SM, Abbafati C, Abbasi N, Abbastabar H, Abd-Allah F, Abdela J, Abdelalim AJTL: Global, regional, and national incidence, prevalence, and years lived with disability for 354 diseases and injuries for 195 countries and territories, 1990-2017: a systematic analysis for the Global Burden of Disease Study 2017. 2018, 392(10159):1789-1858.

5. Rathod S, Pinninti N, Irfan M, Gorczynski P, Rathod P, Gega L, Naeem F: Mental health service provision in low-and middle-income countries. Health services insights 2017, 10:1178632917694350.

6. O'DONNELL K, Wardle J, Dantzer C, Steptoe A: Alcohol consumption and symptoms of depression in young adults from 20 countries. Journal of Studies on Alcohol 2006, 67(6):837-840.

7. Kim E, Song JH, Hwang J-Y, Ahn K, Kim J, Koh YH, Park MH, Jo SA: Obesity and depressive symptoms in elderly Koreans: evidence for the "Jolly Fat" hypothesis from the Ansan Geriatric (AGE) Study. Archives of gerontology and geriatrics 2010, 51(2):231-234.

8. Carpenter KM, Hasin DS, Allison DB, Faith MS: Relationships between obesity and DSM-IV major depressive disorder, suicide ideation, and suicide attempts: results from a general population study. American journal of public health 2000, 90(2):251.

9. Tonidandel S, LeBreton JM: Relative importance analysis: A useful supplement to regression analysis. Journal of Business and Psychology 2011, 26(1):1-9.

10. Azen $\mathrm{R}$, Traxel $\mathrm{N}$ : Using dominance analysis to determine predictor importance in logistic regression. Journal of Educational and Behavioral Statistics 2009, 34(3):319-347. 
11. Park Y, Jung JY, Kim YS, Chung KS, Song JH, Kim SY, Kim EY, Kang YA, Park MS, Chang J: relationship between depression and lung function in the general population in Korea: a retrospective cross-sectional study. International journal of chronic obstructive pulmonary disease 2018, 13:2207.

12. Fidika A, Herle M, Goldbeck L: Symptoms of depression impact the course of lung function in adolescents and adults with cystic fibrosis. BMC pulmonary medicine 2014, 14(1):205.

13. Adewuya AO, Afolabi MO, Ola BA, Ogundele OA, Ajibare AO, Oladipo BF, Fakande I: Relationship between depression and quality of life in persons with HIV infection in Nigeria. The International Journal of Psychiatry in Medicine 2008, 38(1):43-51.

14. Rasquinha M, Acharya B: Relationship between Depression and Quality of Life among Institutionalized Elderly. International Journal of Scientific Research 2013, 2(10).

15. Ghazwin MY, Kavian M, Ahmadloo M, Jarchi A, Javadi SG, Latifi S, Tavakoli SAH, Ghajarzadeh M: The association between life satisfaction and the extent of depression, anxiety and stress among Iranian nurses: a Multicenter Survey. Iranian journal of psychiatry 2016, 11(2):120.

16. Schrag AJJotns: Quality of life and depression in Parkinson's disease. 2006, 248(1-2):151-157.

17. van Oers HA, Haverman L, Olieman JF, Neelis EG, Jonkers-Schuitema CF, Grootenhuis MA, Tabbers MMJCN: Health-related quality of life, anxiety, depression and distress of mothers and fathers of children on Home parenteral nutrition. 2019, 38(4):1905-1912.

18. Siarava E, Hyphantis T, Katsanos AH, Pelidou S-H, Kyritsis AP, Markoula SJS: Depression and quality of life in patients with epilepsy in Northwest Greece. 2019, 66:93-98.

19. Kowal P, Chatterji S, Naidoo N, Biritwum R, Fan W, Lopez Ridaura R, Maximova T, Arokiasamy P, Phaswana-Mafuya N, Williams S: Data resource profile: the World Health Organization Study on global AGEing and adult health (SAGE). International journal of epidemiology 2012, 41(6):16391649.

20. Kowal P, Chatterji S, Naidoo N, Biritwum R, Fan W, Lopez Ridaura R, Maximova T, Arokiasamy P, Phaswana-Mafuya N, Williams SJljoe: Data resource profile: the World Health Organization Study on global AGEing and adult health (SAGE). 2012, 41(6):1639-1649.

21. Tucker-Seeley RD, Harley AE, Stoddard AM, Sorensen GG: Financial hardship and self-rated health among low-income housing residents. Health Education \& Behavior 2013, 40(4):442-448.

22. Luchman JN: Determining subgroup difference importance with complex survey designs: An application of weighted dominance analysis. Survey Practice 2015, 8(5).

23. Glazerman S, Levy DM, Myers D: Nonexperimental versus experimental estimates of earnings impacts. The Annals of the American Academy of Political and Social Science 2003, 589(1):63-93.

24. Gelman A, Meng X-L: Applied Bayesian modeling and causal inference from incomplete-data perspectives: John Wiley \& Sons; 2004.

25. DerSimonian R, Laird NJCct: Meta-analysis in clinical trials. 1986, 7(3):177-188.

26. Zielinski TA, Brown ES, Nejtek VA, Khan DA, Moore JJ, Rush AJJPccttJocp: Depression in asthma: prevalence and clinical implications. 2000, 2(5):153. 
27. Kuehn BMJJ: Asthma linked to psychiatric disorders. 2008, 299(2):158-160.

28. Laforest L, Van Ganse E, Devouassoux G, Bousquet J, Chretin S, Bauguil G, Pacheco Y, Chamba GJJoA, Immunology C: Influence of patients' characteristics and disease management on asthma control. 2006, 117(6):1404-1410.

29. Van Lieshout RJ, MacQueen GM: Relations between asthma and psychological distress: an old idea revisited. In: Allergy and the nervous system. Volume 98, edn.: Karger Publishers; 2012: 1-13.

30. Mrazek DA: Psychiatric symptoms in patients with asthma: Causality, comorbidity, or shared genetic etiology. J Child adolescent psychiatric clinics of North America 2003.

31. Scott KM, Von Korff M, Ormel J, Zhang M-y, Bruffaerts R, Alonso J, Kessler RC, Tachimori H, Karam E, Levinson DJGhp: Mental disorders among adults with asthma: results from the World Mental Health Survey. 2007, 29(2):123-133.

32. Ortega AN, Feldman JM, Canino G, Steinman K, Alegría MJSp, epidemiology p: Co-occurrence of mental and physical illness in US Latinos. 2006, 41(12):927-934.

33. Lehto K, Pedersen NL, Almqvist C, Lu Y, Brew BKJERJ: Asthma and affective traits in adults: a genetically informative study. 2019, 53(5):1802142.

34. Choi HG, Kim J-H, Park J-Y, Hwang YI, Jang SH, Jung K-SJTJoA, Practice Cll: Association Between Asthma and Depression: A National Cohort Study. 2019, 7(4):1239-1245. e1231.

35. Sivertsen H, Bjørkløf GH, Engedal K, Selbæk G, Helvik A-S: Depression and quality of life in older persons: a review. Dementia and geriatric cognitive disorders 2015, 40(5-6):311-339.

36. Hasche LK, Morrow-Howell N, Proctor EK: Quality of life outcomes for depressed and nondepressed older adults in community long-term care. The American Journal of Geriatric Psychiatry 2010, 18(6):544-553.

37. Mendlowicz MV, Stein MB: Quality of life in individuals with anxiety disorders. American Journal of Psychiatry 2000, 157(5):669-682.

38. Hita-Yañez E, Atienza M, Cantero JLJS: Polysomnographic and subjective sleep markers of mild cognitive impairment. 2013, 36(9):1327-1334.

39. Sivertsen H, Bjørkløf GH, Engedal K, Selbæk G, Helvik A-SJD, Disorders GC: Depression and quality of life in older persons: a review. 2015, 40(5-6):311-339.

40. Farabaugh A, Fisher L, Nyer M, Holt D, Cohen M, Baer L, Shapero BG, Huz I, Cardoos A, Fava MJ, 27, 2: Similar changes in cognitions following cognitive-behavioral therapy or escitalopram for major depressive disorder: Implications for mechanisms of change. 2015, 27(2):118-126.

\section{Figures}




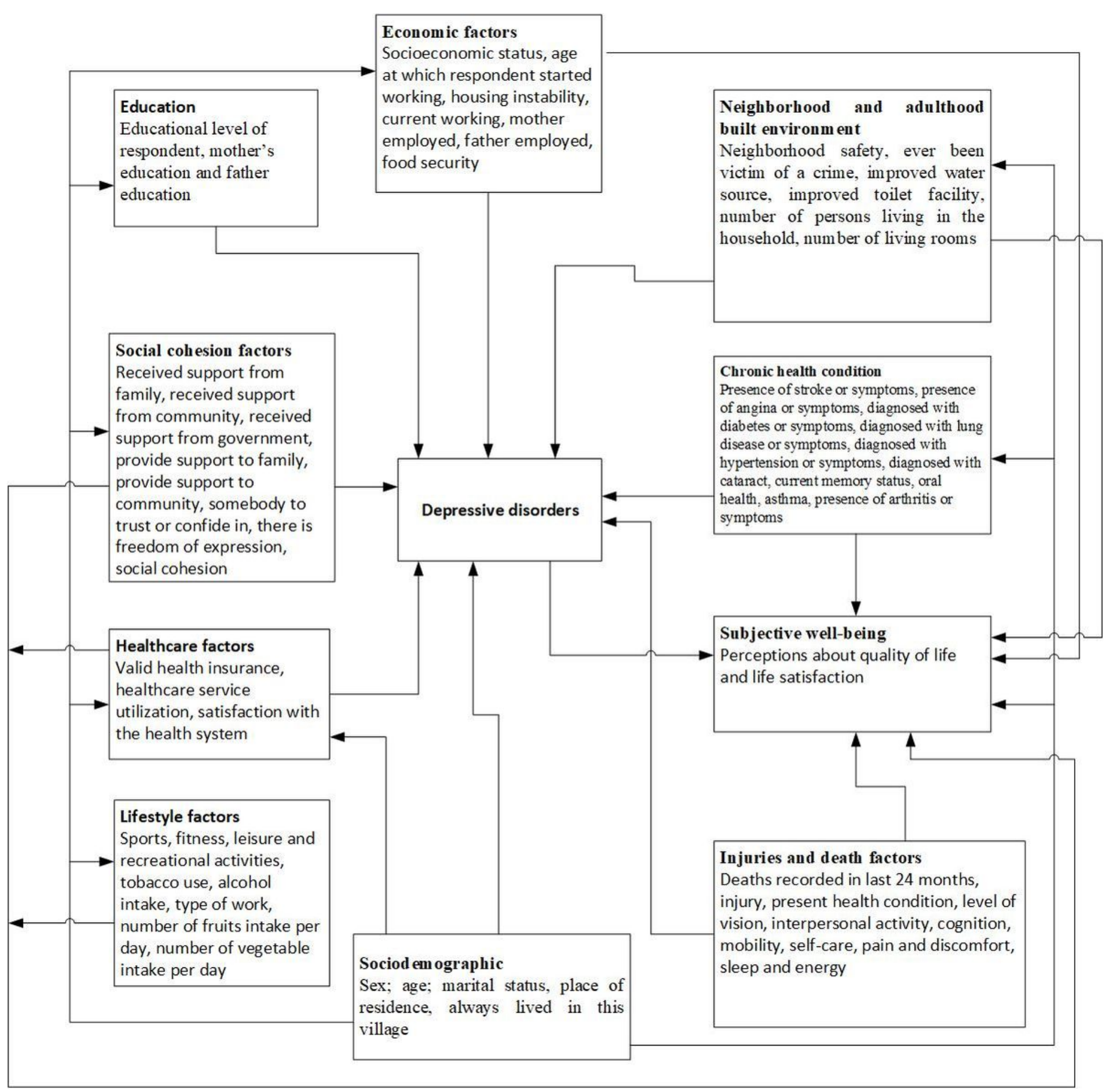

Figure 1

Factors associated with Depressive Disorders-Author's construction

\section{Supplementary Files}

This is a list of supplementary files associated with this preprint. Click to download. 